\title{
The Preparation of Graphene Reinforced Poly(vinyl alcohol) Antibacterial Nanocomposite Thin Film
}

\author{
Yuan-Cheng Cao, Wenjun Wei, Jiyan Liu, Qingliang You, Feiyan Liu, Qian Lan, \\ Chang Zhang, Chang Liu, and Jinxing Zhao \\ Key Laboratory of Optoelectronic Chemical Materials and Devices of Ministry of Education, Jianghan University, \\ Wuhan 430056, China \\ Correspondence should be addressed to Yuan-Cheng Cao; caosome@126.com
}

Received 7 December 2014; Revised 7 January 2015; Accepted 8 January 2015

Academic Editor: Cornelia Vasile

Copyright (C) 2015 Yuan-Cheng Cao et al. This is an open access article distributed under the Creative Commons Attribution License, which permits unrestricted use, distribution, and reproduction in any medium, provided the original work is properly cited.

\begin{abstract}
Methylated melamine grafted polyvinyl benzylchloride ( $\mathrm{mm}-\mathrm{g}-\mathrm{PvBCl})$ was prepared which was used as additive in poly(vinyl alcohol) (PVA) and graphene nanosheets (GNs) were used to reinforce the mechanical strength. Using casting method, antimicrobial nanocomposite films were prepared with the polymeric biocide loading lever of $1 \mathrm{wt} \%$, $5 \mathrm{wt} \%$, and $10 \mathrm{wt} \%$. Thermogravimetric analysis (TGA) characterization revealed the $2.0 \mathrm{wt} \%$ of graphene content in resultant nanocomposites films. XRD showed that the resultant GNs 2 theta was changed from 16.6 degree to 23.3 degree. Using Japanese Industry Standard test methods, the antimicrobial efficiency for the loading lever of $1 \mathrm{wt} \%, 5 \mathrm{wt} \%$, and $10 \mathrm{wt} \%$ was $92.0 \%, 95.8 \%$, and $97.1 \%$, respectively, against gram negative bacteria $E$. coli and $92.3 \%, 99.6 \%$, and $99.7 \%$, respectively, against the gram positive $S$. aureus. These results indicate the prepared nanocomposite films are the promising materials for the food and drink package applications.
\end{abstract}

\section{Introduction}

With the nanoscience and nanotechnology development in materials, nanomaterials which consist of at least one dimension in nanoscale have simulated considerable attention in the research field of advanced materials. Changing of the matrix and nanodimensional phase(s) may result in novel properties due to the dissimilarities in structure and chemistry which are remarkably different from those of the original component materials [1-4]. Polymer nanocomposites are one of these novel nanomaterials which have advantages not only in the reinforcement due to the high area to volume ratio, but also in the physical and engineering properties including fire retardancy, barrier resistance, and conductivity [3-8]. Therefore, various polymer nanocomposites have been developed aiming at different applications such as conductivity enhancement and mechanical improvements [5-10].

Antibacterial polymer nanocomposites have attracted great interests recently, especially in the hygiene products and food packages [1, 10-12], providing improved food safety and longer shelf life. Therefore, antimicrobial polymer nanocomposite packaging is one of the most promising active packaging materials which have high efficiency in antimicroorganisms. The antibacterial ability of the polymer nanocomposites normally is provided by loading antibacterial additives during the processes or by the modification of the polymer nanocomposites with biocidal groups [11-17]. However, due to the toxicity to the human body, not all of the biocide additives reported can be used in the hygiene and food packaging product fields [11, 12]. For example, the inorganic biocide such as silver-based biocides, though it shows strong antibacterial ability, is seldom used in the food package products due to its toxicity to the human body. And the compatibility between the biocide and polymer matrix is another aspect that has to be taken into consideration, as this might affect the mechanical properties or the barrier property of the resultant materials. Consequently, the polymer biocides are the promising biocide especially in antibacterial polymer nanocomposites [13-15].

As graphene/polymer nanocomposites have many promising properties such as barrier property and mechanical reinforcement, graphene was applied in the 
poly(vinyl alcohol) (PVA) matrix in this study in order to improve the PVA-biocide composite material mechanical strength. And at the same time, we are trying to develop the antibacterial graphene/PVA nanocomposite thin film (G/PVA) based on the synthesised polymer biocide and we hope this could lead to a high efficient antibacterial food and drink package materials.

\section{Experimental Section}

2.1. Chemicals and Reagents. Expandable graphene (EG) (100 nm thick) was purchased from Shandong Qingdao Company limited (China), grade ES/350/FS. Poly(vinyl alcohol) (PVA) was purchased from supermarket. Polyvinyl benzylchloride $(\mathrm{PvBCl})$ was purchased from Sigma $(60,000 \mathrm{Da}$ molecular weight). Microscope glass slides $(76 \mathrm{~mm} \times 26 \mathrm{~mm})$ were obtained from Fisher Scientific (UK, FB58622). Sulphuric acid, isopropanol, and potassium dihydrogen phosphate were purchased from Fisher Scientific (UK). Melamine (catalogue no. M2659), 3-bromo propanol (catalogue no. 167169), and dimethyl sulfate (DMS, catalogue no. D186309) and dimethyl sulfoxide (DMSO) were purchased from Sigma Aldrich. Escherichia coli (NCTC 8545) and Staphylococcus aureus (NCTC 7447) of the representative gram negative and gram positive bacteria strains are used in the tests. Nutrient broth (NB), phosphate buffered physiological saline (PBS), and tryptone soya broth (TSB) were purchased from Merck; sodium chloride tablets, plate count agar, and lecithin were purchased from Oxoid. All other chemicals were used as received and the water used in this work was distilled water.

\subsection{Synthesis of Biocide Polymer and Preparation of} PVA/Biocide Polymer Mixture. The synthesis of polymer biocide was carried out by following the related reference [4]. Briefly, melamine (5 g) was first dissolved in DMSO and then excess DMSO was added dropwise under magnetic stirring to obtain the resultant methylated melamine. Then $10 \mathrm{~g}$ of polyvinyl benzylchloride $(\mathrm{PvBCl})$ was dissolved in $100 \mathrm{~mL}$ Toluene at $70^{\circ} \mathrm{C}$ in a conical flask equipped with a reverse condenser. $2 \mathrm{~g}$ (10 $\mathrm{mmol})$ of methylated melamine was added to the polymer solution resulting in 1:2 molar ratio of vinylbenzyl chloride to tertiary amine. The reaction in the mixture was carried out at $70^{\circ} \mathrm{C}$ for 24 hours under constant stirring. $2 \mathrm{~mL}$ of 3 -bromo propanol was added into the flask which was followed by further reaction for 24 hours. Precipitation and purification were carried out to obtain the quaternary ammonium modified $\mathrm{PvBCl}\left(\mathrm{qPvB} / \mathrm{Cl}^{-}\right)$ polymer biocide. This synthesis route is shown in Figure 1.

\subsection{Preparation of Expanded Graphene and Exfoliation} into Graphene Nanosheets. Expandable graphene powders (100 nm thick) were irradiated with microwaves for about 15 seconds in a microwave oven (NN-E255W, Panasonic, UK) to obtain expanded graphene. An expansion of about 200 times the original size of the graphene was obtained [5-7]. For the exfoliation process, $0.1 \mathrm{~g}$ of the expanded graphene (EG) was dispersed in $100 \mathrm{~mL}$ distilled water (to make $0.1 \% \mathrm{w} / \mathrm{v}$ ) and was first blended for a total of 10 minutes using a blender (Panasonic, UK) to aid the exfoliation. This was then followed by ultrasonic treatment using a Sonicor SC-120TH ultrasonic bath $(150 \mathrm{~W})$ at $65^{\circ} \mathrm{C}$ in $20 \mathrm{~mL}$ batches until stable uniform aqueous dispersion of graphene nanosheets (GNs) was obtained and this process is shown in Figure 2(a). The exfoliation process lasted for about 6 hours.

2.4. Preparation of Graphene/PVA-Biocide Films. To prepare the graphene/PVA-biocide films, PVA and biocide were first both dissolved and mixed together thoroughly in N,Ndimethyl formamide (DMF) solvent at $80^{\circ} \mathrm{C}$. And expended graphene was mixed with PVA to prepare the graphene/PVA stock. Three graphene/PVA-biocide mixtures with different concentrations of biocide $(1 \%, 5 \%$, and $10 \%)$ were prepared. Briefly, the graphene/PVA-1\% biocide, graphene/PVA$5 \%$ biocide, and graphene/PVA-10\% biocide mixtures were prepared by adding $0.1 \mathrm{~g}, 0.5 \mathrm{~g}$, and $1.0 \mathrm{~g}$ biocide, respectively, into $10 \mathrm{~mL}$ of graphene/PVA stock. This was then followed by dissolving each mixture in $20 \mathrm{~mL}$ DMF at $80^{\circ} \mathrm{C}$ with continuous stirring. These graphene/PVA-biocide mixtures were then used in the preparation of the antimicrobial nanocomposite films in the tests. In addition, diluted PVA was prepared by dissolving $10 \mathrm{~mL}$ PVA in $20 \mathrm{~mL} \mathrm{DMF}$ at $80^{\circ} \mathrm{C}$ and was used as blank. The final thickness of the films was $0.1 \mathrm{~mm}$. The typical image of the as-prepared film was shown in Figure 2(b).

2.5. Characterisation. The antimicrobial behaviour of the graphene/PVA-biocide nanocomposite films against gram negative Escherichia coli (NCTC 8545) and gram positive Staphylococcus aureus (NCTC 7447) was evaluated using the Japanese Industrial Standard testing method (JIS Z 2801). In brief, bacteria cells cultured in broth (test inoculums) were placed on the surface of the test samples, namely, graphene/PVA-(1\% biocide), graphene/PVA-(5\% biocide), and graphene/PVA-(10\% biocide) nanocomposite films. A graphene/PVA nanocomposite film, without biocide, was used as the standard control sample. These thin films were cut into $25 \mathrm{~mm} \times 25 \mathrm{~mm}$. Each sample was prepared in duplicate. The inoculated nanocomposite films were then covered with polyethylene films $(20 \mathrm{~mm} \times 20 \mathrm{~mm})$ to facilitate the contact between the bacteria cells and the sample. These were incubated for 24 hours in a $37^{\circ} \mathrm{C}$ incubator. The viable bacterial cell count (in $\mathrm{CFU} / \mathrm{mL}$ ) for all the samples was determined immediately after inoculation and after incubation for 24 hours by using the agar plate culture method. The number of viable cells of bacterial inoculum on each sample was calculated to be $2.35 \pm 0.05 \times 10^{4} \mathrm{CFU} / \mathrm{mL}$ for $E$. coli inoculum and $2.01 \pm 0.25 \times 10^{5} \mathrm{CFU} / \mathrm{mL}$ for $S$. aureus. The sample was thoroughly washed by ethanol wiper to clean both surfaces before being placed in different labelled sterile Petri dishes. And $0.2 \mathrm{~mL}$ of the test inoculum was dropped, using a pipette, on the surface of each sample. Each sample was carefully covered by polyethylene films to allow the inoculum to spread evenly over the surface of the samples. The Petri dishes were capped and incubated for 24 hours at $37^{\circ} \mathrm{C}$ and $\sim 90 \%$ relative humidity. For enumeration of the number of viable bacteria cells on each sample after the previous culture, $10 \mathrm{~mL}$ washing broth of each inoculated sample was used to completely 


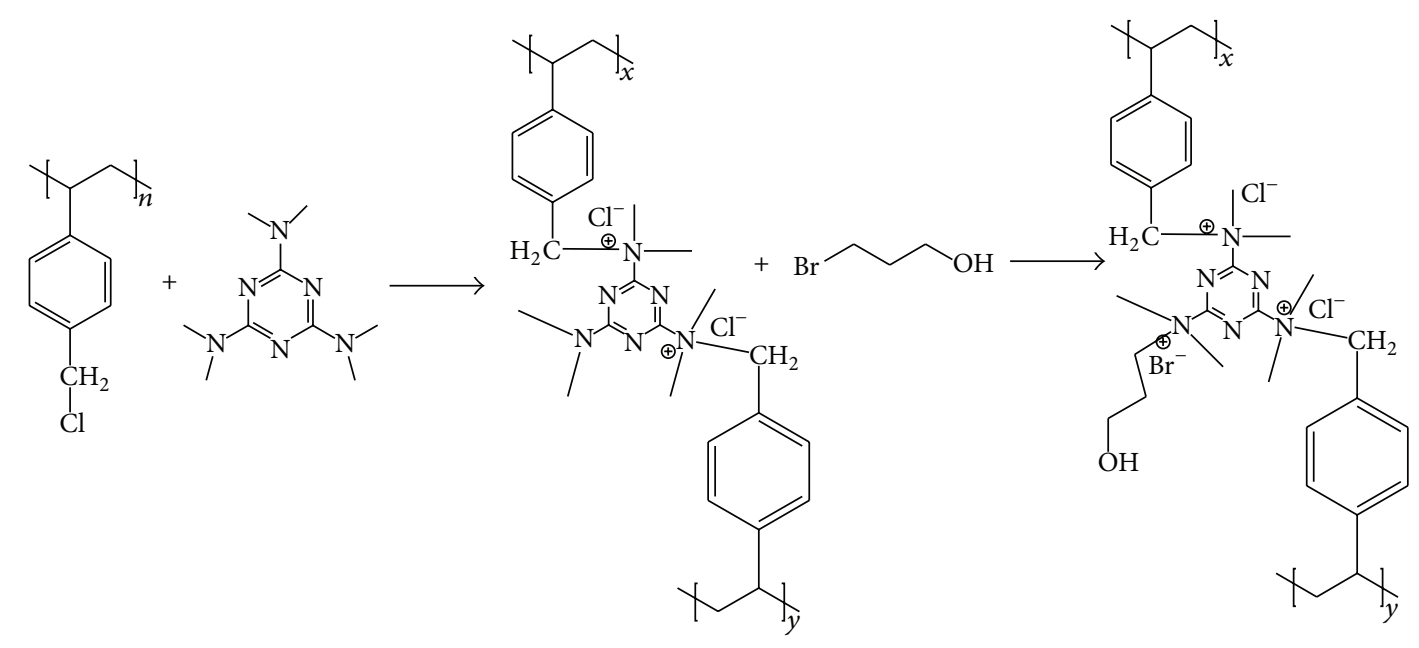

FIGURE 1: Synthesis and structure of polymer biocide which contains quaternary ammonium salts (QAS) groups.

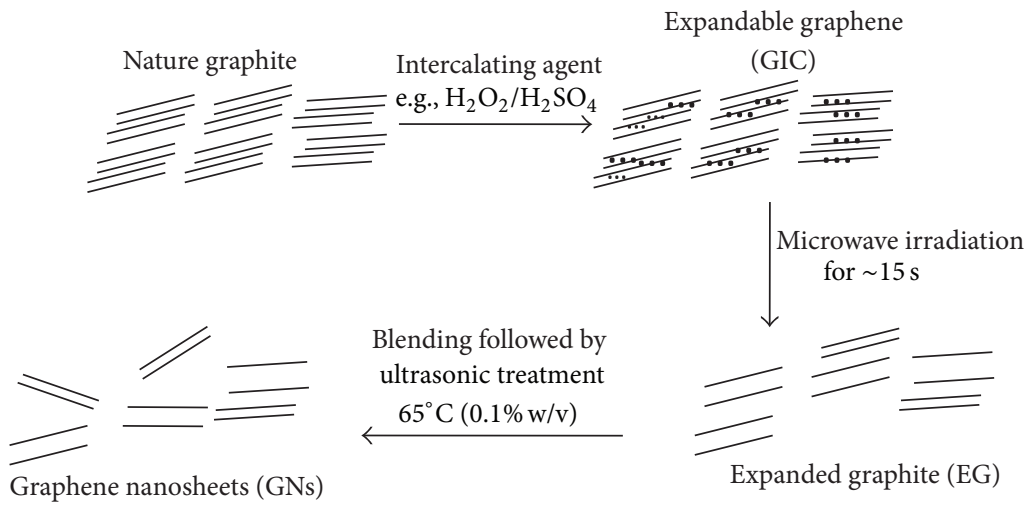

(a)

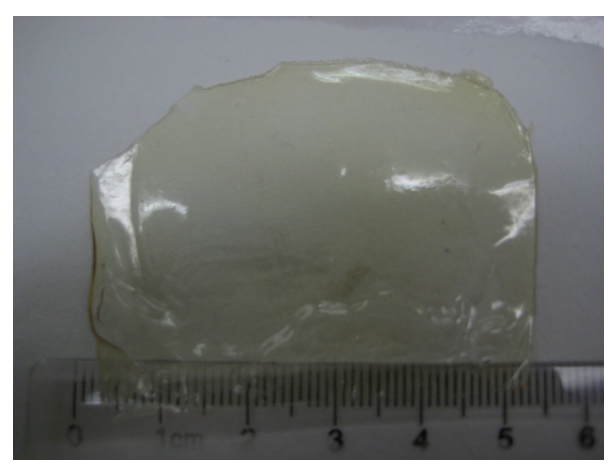

(b)

FIGURE 2: A schematic illustration of the preparation of graphene nanosheets (GNs) from natural graphene (a) and the photo of resultant $10 \%$ biocide thin film (b).

wash out the bacterial cells from the sample surface. And then $1 \mathrm{~mL}$ of each washing broth was used to make 10-fold serial dilutions $\left(10^{1}\right.$ to $10^{5}$ dilutions) in phosphate buffered physiological saline (PBS). From each of the washings and their respective dilutions, $1 \mathrm{~mL}$ was added to different Petri dishes and then followed by adding $15 \mathrm{~mL}$ of the plate count agar. Then these dishes were incubated at $37^{\circ} \mathrm{C}(\sim 90 \%$ relative humidity) for 48 hours. After incubation, the colonies on each of the dishes were counted for calculating the number of viable cells. The $\mathrm{CFU} / \mathrm{mL}$ of each replica was determined and their mean values were recorded.

TGA was performed under compressed air using a TGASDTA $851^{\mathrm{e}}$ thermogravimetric analyzer (Mettler-Toledo, UK). Samples (about $2 \mathrm{mg}$ each) were heated from $30^{\circ} \mathrm{C}$ to $900^{\circ} \mathrm{C}$ at $10^{\circ} \mathrm{C} /$ minute and the percentage weight loss of each sample was recorded as a function of temperature using the STAR $^{\mathrm{e}}$ software 9.10.

All the samples for XRD were determined by powder Xray diffraction (XRD) analyses with Hilton brooks modified Philips X-ray diffractometer $(\mathrm{Cu} \mathrm{K} \alpha, \lambda=1.5418 \AA)$ and generated at $30 \mathrm{kV}, 30 \mathrm{~mA}$. Scattering angles were ranged from $1^{\circ}$ to $60^{\circ}$.

\section{Results and Discussion}

In this work, polymer biocide was synthesized from methylated melamine (M-melamine) which contains three trimethylamine groups to react with poly vinyl benzylchloride to produce quaternary ammonium groups grafted polymer materials (Figure 1). Graphene was used as polymer filler to reinforce the PVA mechanical strength and improve the barrier property for the food package applications where the air barrier plays an important role in the food protection $[16,17]$. Here we are trying to exfoliate the natural graphene particles into nanosheets under the chemical environments by using the expandable graphene and the process is shown in Figure 2(a). For this feasibility study, PVA was used as the polymer matrix for the preparation of biocide/graphene nanocomposites. And in this preparation process, the polymers used were either pure PVA (in graphene/PVA 


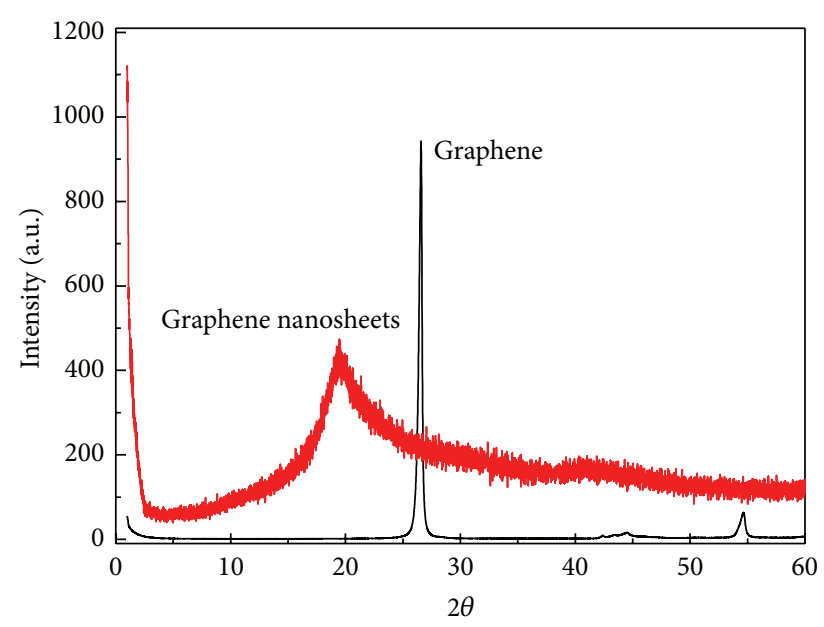

FIGURE 3: XRD spectra of the graphene and expanded graphene.

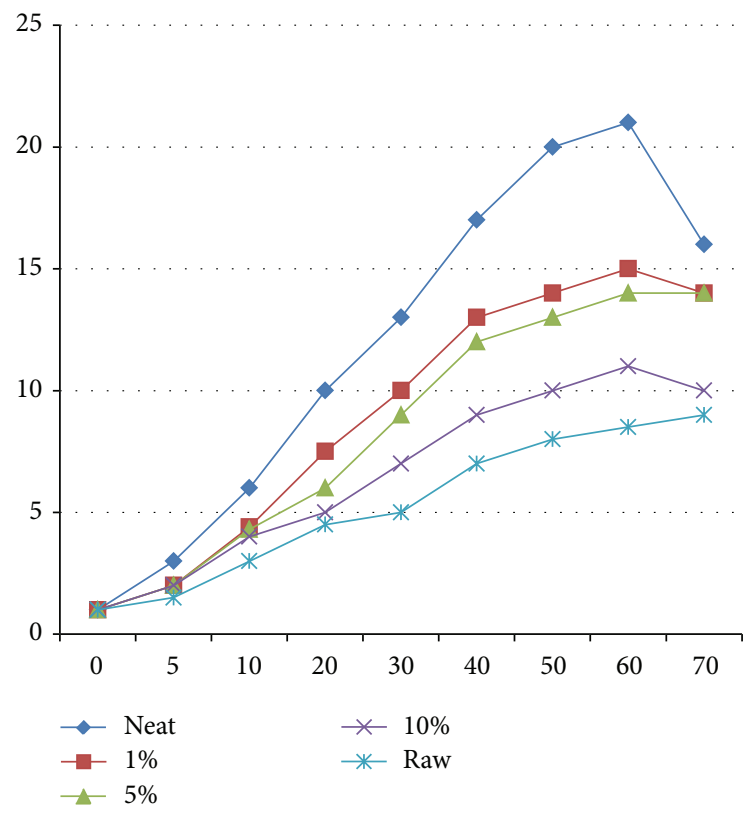

FIGURE 4: Mechanical strength of the graphene reinforced composites materials.

samples, G/PVA) or PVA-biocide mixture with different concentration, namely, $1 \%, 5 \%$, and $10 \%$ (Figure 2(b)).

XRD tests in Figure 3 showed that the expanded graphene 2 theta $=26.5$ degree which means the gallery distance is $0.3 \mathrm{~nm}$, and the resultant graphene nanosheets 2 theta were in the range of 16.6 degree to 23.3 degree which indicates that the gallery distances increased according to Bragg equations.

Tensile tests were carried out on all the samples and the results are shown in Figure 4 . The stress-strain curve for the neat PVA film showed that the tensile strength was 8.3 $\mathrm{MPa}$ and the fractured elongation was about $85 \%$. For the graphene reinforced films, the tensile stresses were improved to $24.2 \mathrm{MPa}$, and the fractured elongation was $60 \%$. However, when the loading of biocide increased from $1 \%$ to $10 \%$, the tensile stresses were decreased from 15.1 MPa to 9.8 $\mathrm{MPa}$. It

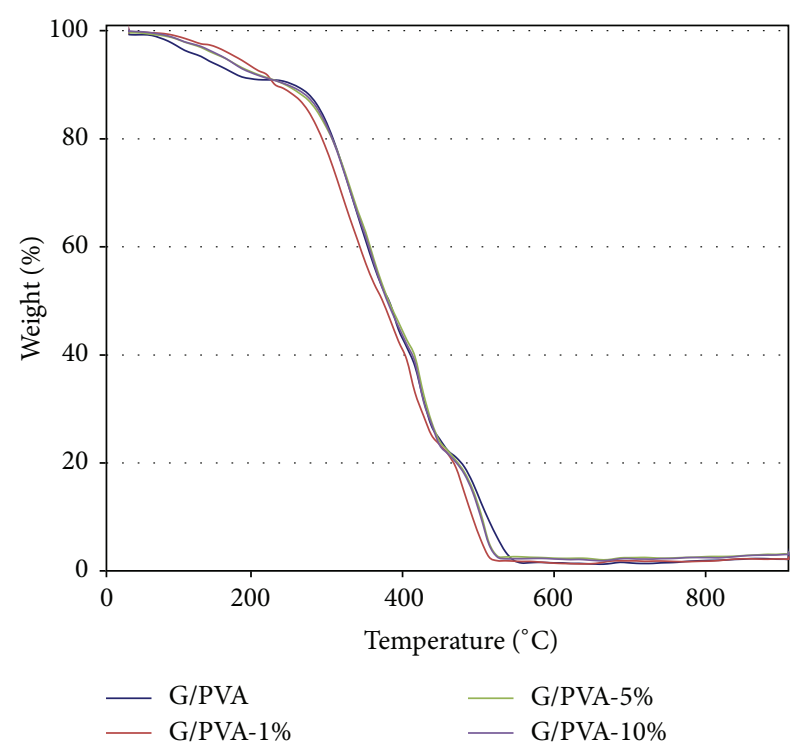

FIgURE 5: Thermogravimetric analysis results of G/PVA, G/PVA-(1\% biocide), G/PVA-(5\% biocide), and G/PVA-( $10 \%$ biocide). The data were obtained under compressed air at $10^{\circ} \mathrm{C} /$ minute.

showed that when the loading was below $5 \%$, the addition of biocide showed little effect to the decrease of the mechanical strength.

Thermogravimetric analysis (TGA) results in Figure 5 showed that all four samples exhibited two major stages: first stage was below $200^{\circ} \mathrm{C}$ and the other was above $265^{\circ} \mathrm{C}$. The weight loss for the first stage below $200^{\circ} \mathrm{C}$ was contributed by the release of water and solvent from the test samples. This weight loss accounted for $9.0 \%$ in G/PVA film, $5.0 \%$ in G/PVA-(1\% biocide) film, $8.0 \%$ in G/PVA-( $5 \%$ biocide) film, and $10.5 \%$ in G/PVA-(10\% biocide) nanocomposite films. The second weight loss was observed in the temperature range $265^{\circ} \mathrm{C} \sim 515^{\circ} \mathrm{C}$ which was associated with the decomposition of the polymers (pure PVA and polymer biocide) presented in these test samples. In the G/PVA nanocomposite film, $89 \%$ weight loss was a result of the decomposition of PVA. In the G/PVA-(1\% biocide), G/PVA-(5\% biocide), and G/PVA(10\% biocide) nanocomposite films, $92.9 \%, 89.5 \%$, and $89.3 \%$ weight losses, respectively, were associated with the decomposition of PVA and biocide. The remaining 2.0\%, 2.1\%, 2.5\%, and $2.7 \mathrm{wt} \%$ residues were the content of graphene in the nanocomposite films. Therefore, from the analysis results of TGA, the ratio of graphene to polymer in the nanocomposite films was $2 \%$. And this content of graphene can effectively improve the mechanical stress of the PVA films.

In order to test the biocide activity of these nanocomposite thin films, a standardized testing method, Japanese Industry Standard ( $\mathrm{Z}$ 2801), was used to evaluate the antimicrobial activity and efficacy of antimicrobial products against bacteria in direct contact with its surface [18]. The details of this procedure are shown in Figure 6.

The antimicrobial behaviour of the antimicrobial nanocomposite films against $E$. coli cells was tested and the results are shown in Figure 7. The population of E. coli cells 


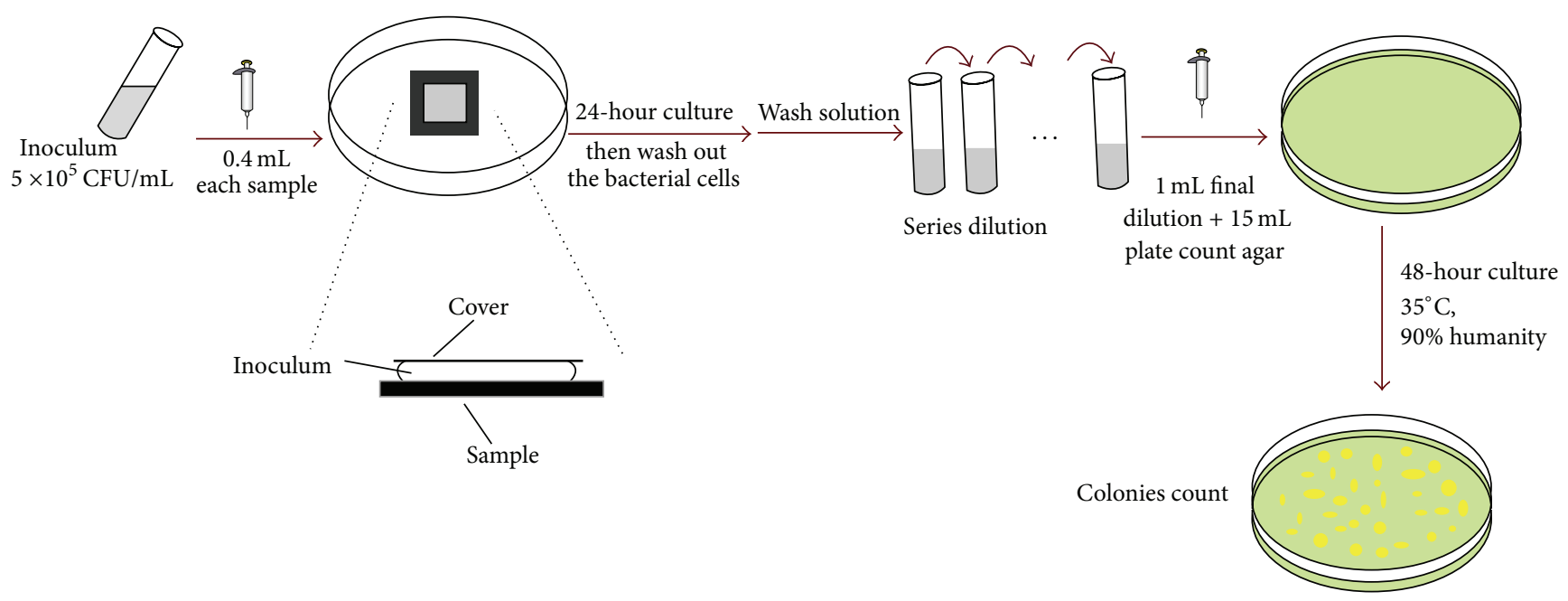

FIGURE 6: The illustration of Japanese Industry Standard (Z2801) antibacterial test procedures.

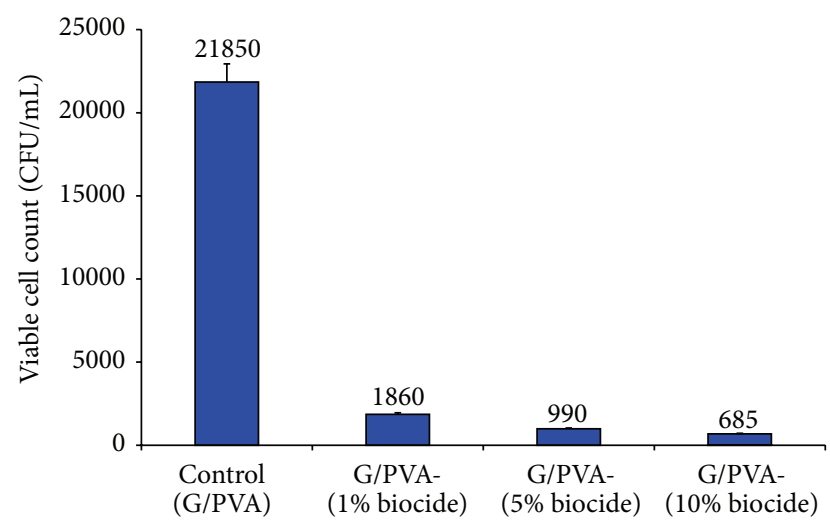

Figure 7: Antimicrobial test of the G/PVA-biocide antimicrobial nanocomposite films against $E$. coli after incubation at $37^{\circ} \mathrm{C}$ for 24 hours and the control test film was G/PVA.

immediately after inoculation on each sample was $(2.35 \pm$ $0.05) \times 10^{4} \mathrm{CFU} \mathrm{mL} \mathrm{mL}^{-1}$. The viable cell count of $E$. coli on the surface of the G/PVA, G/PVA-(1\% biocide), G/PVA-(5\% biocide), and G/PVA-(10\% biocide) nanocomposite films after 24 hours incubation was $(2.19 \pm 0.16) \times 10^{4} \mathrm{CFU} \mathrm{mL}^{-1}$, $(1.86 \pm 0.08) \times 10^{3} \mathrm{CFU} \mathrm{mL}^{-1},(9.90 \pm 0.85) \times 10^{2} \mathrm{CFU} \mathrm{mL}^{-1}$, and $(6.85 \pm 0.35) \times 10^{2} \mathrm{CFU} \mathrm{mL}^{-1}$, respectively. As we can see from the results, the percentage decrease in viable $E$. coli cells on the surface of the G/PVA-(1\% biocide), G/PVA(5\% biocide), and G/PVA-(10\% biocide) antimicrobial nanocomposite films was $92.0 \%, 95.8 \%$, and $97.1 \%$, respectively, compared to the control test film G/PVA. It can be seen from these results that even at a $1 \%$ biocide to PVA concentration in the nanocomposite films, $92 \%$ of the total E. coli cells were rendered nonviable after 24 hours of contact. However, there were no much differences in percentage population decrease as the concentration of biocide increased from $1 \%$ to $5 \%$ (3.8\% population decrease) and from $5 \%$ to $10 \%$ (1.3\% population decrease). These results indicate that the graphene nanocomposite film has strong

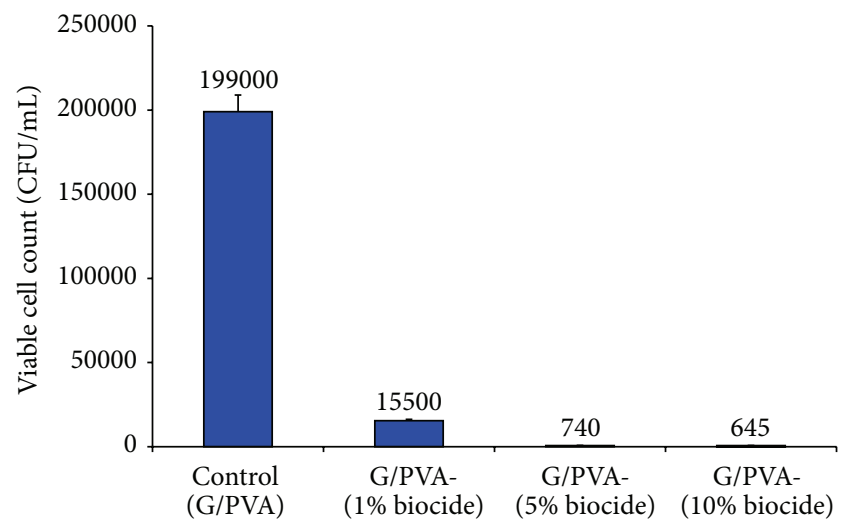

FIgURE 8: Antimicrobial test of the G/PVA-biocide antimicrobial nanocomposite films against $S$. aureus after incubation at $37^{\circ} \mathrm{C}$ for 24 hours and the control test film was G/PVA.

antibacterial activity to the gram negative even at $5 \%$ load lever.

Further tests were carried out against the gram positive bacterial reprehensive $S$. aureus under the same conditions and the results are shown in Figure 8. The population of $S$. aureus cells immediately after inoculation of each sample was $(2.01 \pm 0.25) \times 10^{5} \mathrm{CFU} \mathrm{mL}^{-1}$. The number of viable $S$. aureus cells on the surface of the G/PVA, G/PVA-(1\% biocide), G/PVA-(5\% biocide), and G/PVA-(10\% biocide) nanocomposite films after 24 hours was $(1.99 \pm 0.01) \times 10^{5} \mathrm{CFU} \mathrm{mL}^{-1}$, $(1.55 \pm 0.10) \times 10^{4} \mathrm{CFU} \mathrm{mL}^{-1},(7.40 \pm 1.69) \times 10^{2} \mathrm{CFU} \mathrm{mL}^{-1}$, and $(6.45 \pm 0.35) \times 10^{2} \mathrm{CFU} \mathrm{mL}^{-1}$, respectively. The percentage decrease in the number of viable $S$. aureus cells on the surface of the G/PVA-(1\% biocide), G/PVA-(5\% biocide), and G/PVA-(10\% biocide) antimicrobial nanocomposite films was $92.3 \%, 99.6 \%$, and $99.7 \%$, respectively. These results indicate that the test films based on biocide are also effective in killing the gram positive bacteria such as $S$. aureus cells.

From the antimicrobial test results, shown in Figures 7 and 8 , the antimicrobial activity of the antimicrobial 


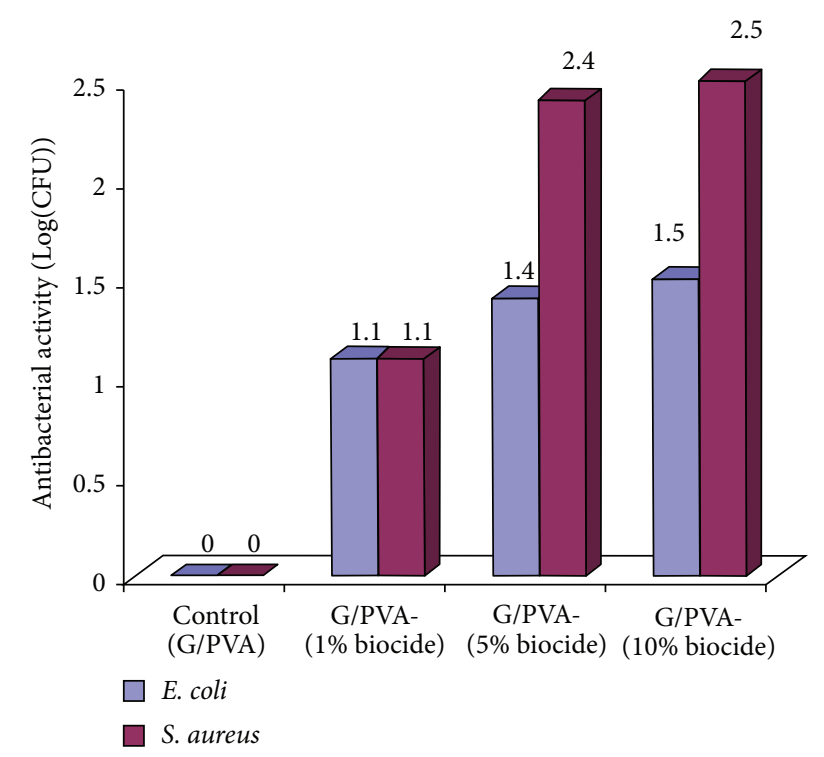

FIGURE 9: Comparison of the antimicrobial activity of the G/PVAbiocide antimicrobial nanocomposite films against $E$. coli and $S$. aureus.

nanocomposite films against E. coli and S. aureus was calculated from this formula:

$$
R=\log \left(\frac{B}{A}\right)-\log \left(\frac{C}{A}\right)=\log \left(\frac{B}{C}\right),
$$

where $R$ = value of antimicrobial activity; $A$ = average number of viable cells on the control (G/PVA) immediately after inoculation; $B=$ average number of viable cells on the control (G/PVA) after 24 hours contact; and $C=$ average number of viable cells on the antimicrobial test sample after 24 hours contact.

The results are shown in Figure 9. It can be seen from the results that the antimicrobial nanocomposite films exhibited very strong antimicrobial activity against both the gram negative $E$. coli and gram positive $S$. aureus bacteria strains tested. In both cases the blank nanocomposite films (without biocide) exhibited no significant antimicrobial activity. It is also clear from these results that the antimicrobial activity of the nanocomposite films increases with an increase in concentration of biocide. However, when the biocide concentration is higher than $5 \%$, the activity does not change much. For example, the antimicrobial activity of the nanocomposites with $1 \%$ and $5 \%$ biocide to PVA showed antimicrobial activity values of 1.1 and 1.4 , respectively, against $E$. coli and 1.1 and 2.4, respectively, against $S$. aureus, while when the biocide concentration increases to $10 \%$, this value only slightly changed to 1.5 and 2.5 , respectively. This, however, suggests that the biocide at $5 \%$ in the nanocomposite films may have reached a concentration high enough to exhibit maximum antimicrobial activity. The quaternary ammonium salts (QAS) present in the biocide, first, require contact with the bacteria cells in order to gain access to their target site (the cell membrane) $[13,19,20]$. The presence of active groups in the biocide provides a positive charge density which attracts the negatively charged bacteria cells to the biocide. Thus, as the concentration of biocide in the nanocomposite films increase, the localized positive charge density increases too; this facilitates the electrostatic attraction of more bacteria cells to the biocide. Also, the presence of other active groups in the biocide, such as hydroxyl $\left(\mathrm{OH}^{-}\right)$groups and possibly carboxylic groups $\left(\mathrm{COO}^{-}\right)$, may have contributed to the strong antimicrobial activity of the biocide [13-17].

Furthermore, the higher biocide concentration (5\%) seems more effective against the gram positive bacteria $S$. aureus (the value is 2.4) than the negative bacteria $E$. coli (where the value is 1.4). A possible explanation for this would be the difference in their membrane structure. As it is generally known, gram negative bacteria cells possess an additional lipopolysaccharide (LPS) layer in their outer cell wall which is lacking in gram positive cells. Therefore it is logical to assume that this supplementary LPS layer provides an additional barrier, for $E$. coli cells, against the penetration of the biocide [11-13, 17-20].

\section{Conclusions}

This feasibility study work demonstrated a simple route to prepare graphene reinforced nanocomposite material and the polymeric biocide can be successfully introduced into the resultant nanocomposite materials. Furthermore, this biocide based graphene nanocomposite thin film demonstrated high effective antibacterial activity against both gram negative and gram positive bacteria at a relative low lever load. This graphene nanocomposite thin film could be the promising materials in the food and drink package applications and the hygiene products industry could also benefit from this study.

\section{Conflict of Interests}

The authors declare that there is no conflict of interests regarding the publication of this paper.

\section{Authors' Contribution}

Feiyan Liu, Qian Lan, Chang Zhang, Chang Liu, and Jinxing Zhao equally contributed to this work.

\section{Acknowledgments}

The project was sponsored by the Scientific Research Initial funding for the advanced talent of Jianghan University, Hubei Province Innovative Young Research Team in Universities (T201318), and Hubei Provincial Key Natural Science Foundations (2014CFA098).

\section{References}

[1] M. Ghaffari-Moghaddam and H. Eslahi, "Synthesis, characterization and antibacterial properties of a novel nanocomposite based on polyaniline/polyvinyl alcohol/Ag," Arabian Journal of Chemistry, vol. 7, no. 5, pp. 846-855, 2014.

[2] S. Sinha Ray and M. Okamoto, "Polymer/layered silicate nanocomposites: a review from preparation to processing," Progress in Polymer Science (Oxford), vol. 28, no. 11, pp. 1539-1641, 2003. 
[3] A. I. Alateyah, H. N. Dhakal, Z. Y. Zhang, and B. Aldousiri, "Low velocity impact and creep-strain behaviour of vinyl ester matrix nanocomposites based on layered silicate," International Journal of Polymer Science, vol. 2014, Article ID 541096, 10 pages, 2014.

[4] Y.-C. Cao, X. Wang, M. Mamlouk, and K. Scott, "Preparation of alkaline anion exchange polymer membrane from methylated melamine grafted poly(vinylbenzyl chloride) and its fuel cell performance," Journal of Materials Chemistry, vol. 21, no. 34, pp. 12910-12916, 2011.

[5] X. Zhang, Y.-P. Zheng, R.-L. Yang, and H.-C. Yang, "Nanocomposites with liquid-like multiwalled carbon nanotubes dispersed in epoxy resin without solvent process," International Journal of Polymer Science, vol. 2014, Article ID 712637, 6 pages, 2014.

[6] W. Gu, W. Zhang, X. Li et al., "Graphene sheets from worm-like exfoliated graphite," Journal of Materials Chemistry, vol. 19, no. 21, pp. 3367-3369, 2009.

[7] A. Guillet, E. Y. Nzoma, and P. Pareige, "A new processing technique for copper-graphite multifilamentary nanocomposite wire: Microstructures and electrical properties," Journal of Materials Processing Technology, vol. 182, no. 1-3, pp. 50-57, 2007.

[8] W. Wang, S. Liao, M. Liu, Q. Zhao, and Y. Zhu, "Polymer composites reinforced by nanotubes as scaffolds for tissue engineering," International Journal of Polymer Science, vol. 2014, Article ID 805634, 14 pages, 2014.

[9] L. Ramos-Galicia, L. N. Mendez, A. L. Martínez-Hernández et al., "Improved performance of an epoxy matrix as a result of combining graphene oxide and reduced graphene," International Journal of Polymer Science, vol. 2013, Article ID 493147, 7 pages, 2013.

[10] J. Xu, Y. Hu, L. Song, Q. Wang, W. Fan, and Z. Chen, "Preparation and characterization of poly(vinyl alcohol)/graphite oxide nanocomposite," Carbon, vol. 40, no. 3, pp. 450-451, 2002.

[11] H. M. C. de Azeredo, "Nanocomposites for food packaging applications," Food Research International, vol. 42, no. 9, pp. 1240-1253, 2009.

[12] J. Markarian, "Antimicrobials find new healthcare applications," Plastics, Additives \& Compounding, vol. 11, no. 1, pp. 18-22, 2009.

[13] G. Lu, D. Wu, and R. Fu, "Studies on the synthesis and antibacterial activities of polymeric quaternary ammonium salts from dimethylaminoethyl methacrylate," Reactive and Functional Polymers, vol. 67, no. 4, pp. 355-366, 2007.

[14] M. Marini, M. Bondi, R. Iseppi, M. Toselli, and F. Pilati, "Preparation and antibacterial activity of hybrid materials containing quaternary ammonium salts via sol-gel process," European Polymer Journal, vol. 43, no. 8, pp. 3621-3628, 2007.

[15] G. Liu, G. Wu, C. Jin, and Z. Kong, "Preparation and antimicrobial activity of terpene-based polyurethane coatings with carbamate group-containing quaternary ammonium salts," Progress in Organic Coatings, vol. 80, pp. 150-155, 2015.

[16] H. Dallyn and D. Shorten, "Hygiene aspects of packaging in the food industry," International Biodeterioration, vol. 24, no. 4-5, pp. 387-392, 1988.

[17] P. Appendini and J. H. Hotchkiss, "Review of antimicrobial food packaging," Innovative Food Science and Emerging Technologies, vol. 3, no. 2, pp. 113-126, 2002.

[18] Japanese Industry Standard, "Antimicrobial products—-test for antimicrobial activity and efficacy," Tech. Rep. JIS Z 2801, Japanese Standards Association, 2000.
[19] K. Dopierala and K. Prochaska, "The effect of molecular structure on the surface properties of selected quaternary ammonium salts," Journal of Colloid and Interface Science, vol. 321, no. 1, pp. 220-226, 2008.

[20] J. Meng, X. Zhang, L. Ni et al., "Antibacterial cellulose membrane via one-step covalent immobilization of ammonium/ amine groups," Desalination, vol. 359, pp. 156-166, 2015. 

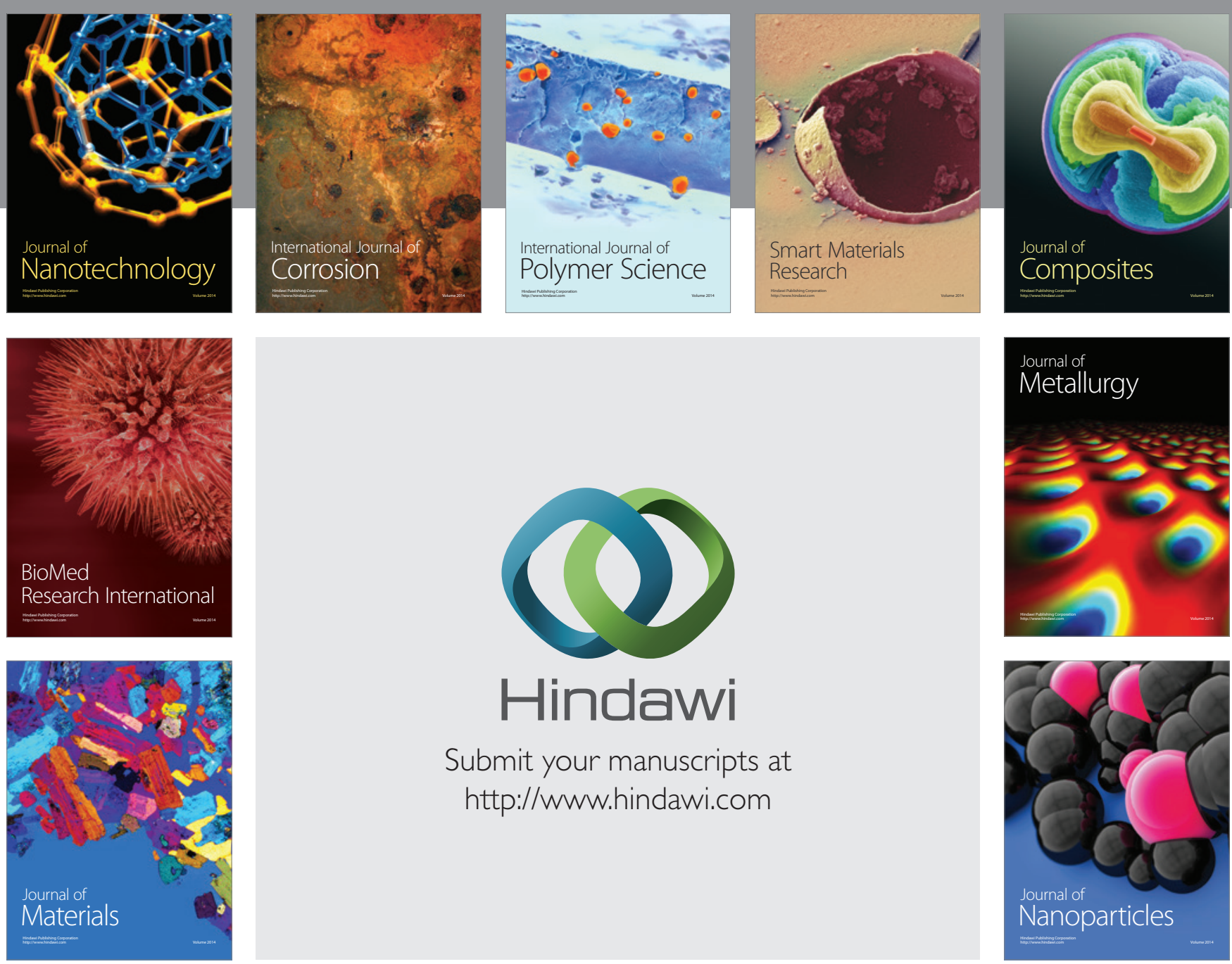

Submit your manuscripts at http://www.hindawi.com
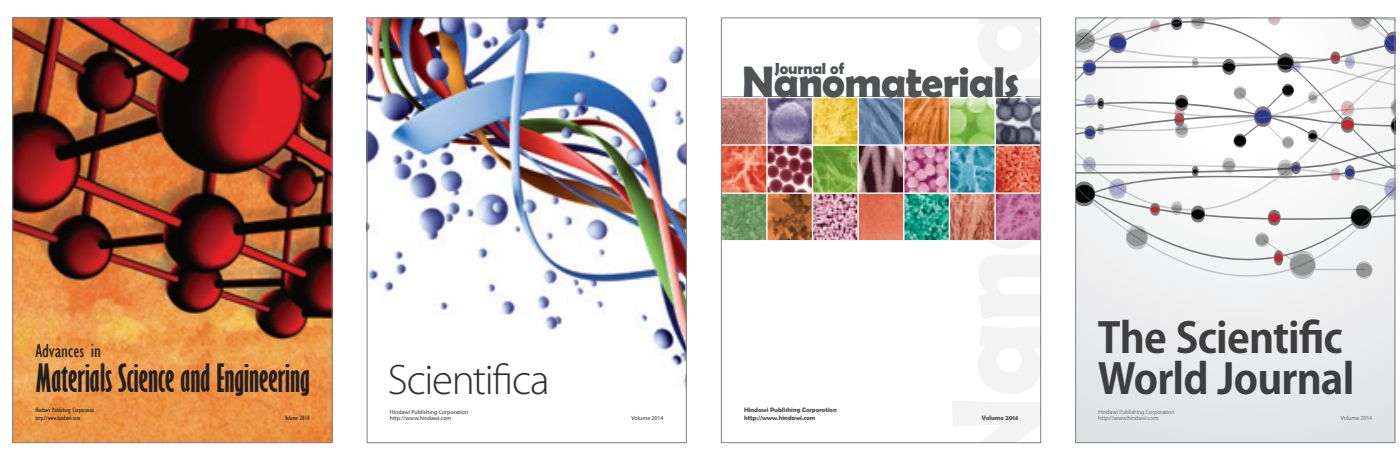

\section{The Scientific World Journal}
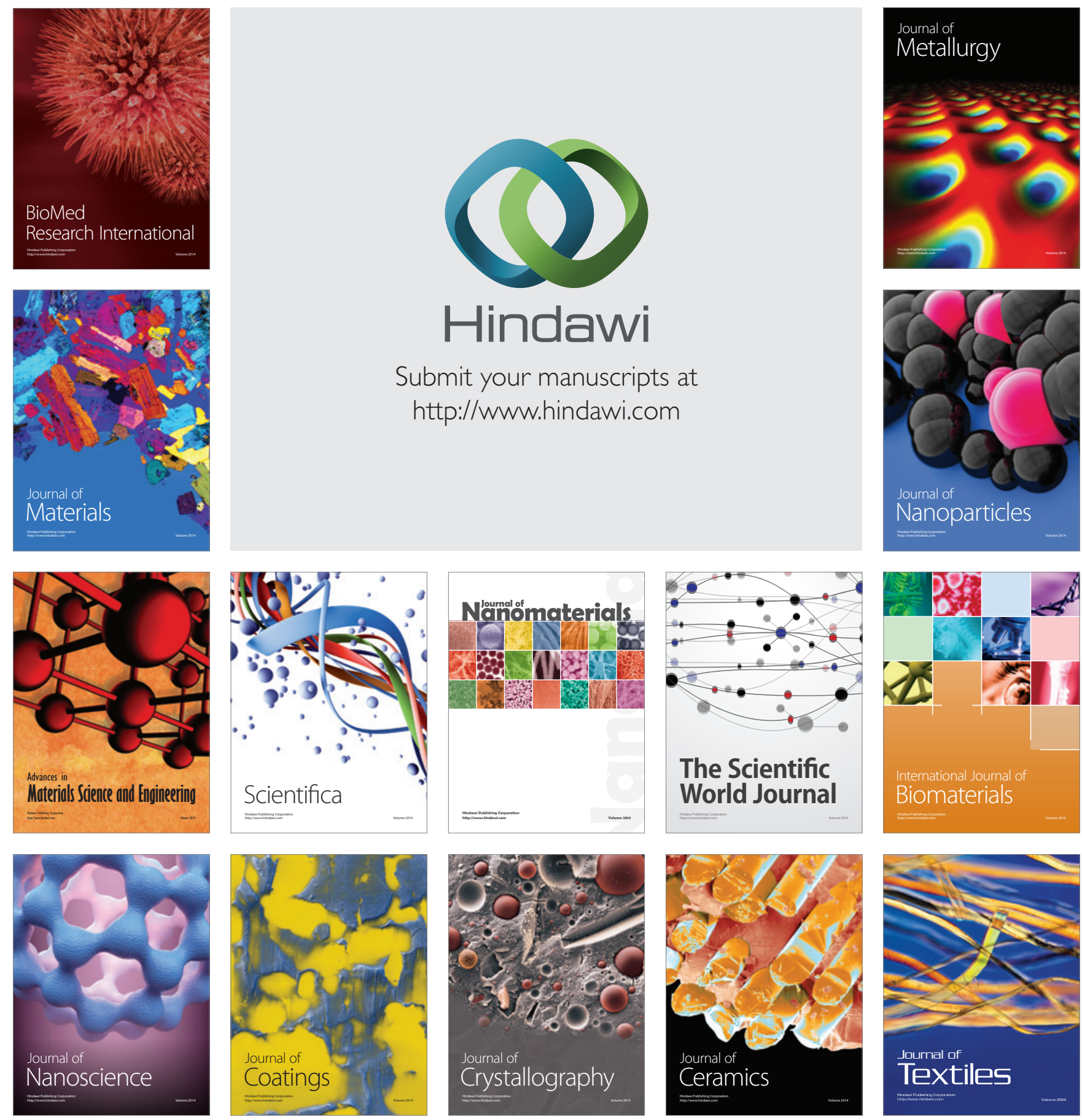